\title{
7
}

\section{Higher-Level Learning: The First Step toward More Significant Learning}

\section{Dee Fink}

University of Oklahoma

In order to design significant learning experiences for students, teachers first need to be able to formulate powerful and challenging goals for their courses. This essay describes a taxonomy of higher-level learning that consists of six kinds of learning: foundational knowledge, application, integration, the buman dimension, motivation, and learning how to learn. The argument is made that this taxonomy goes beyond the familiar taxonomy of Benjamin Bloom and encompasses a wide range of goals that are currently advocated by many national organizations and scholars in bigher education. The taxonomy can be used to design better courses, choose among alternative teaching strategies, and evaluate teaching.

\section{INTRODUCTION}

For the past 20 years, I have been working as an instructional consultAnt with faculty members at my institution to help them find ways to improve their teaching. One consequence of this activity is that I have found myself on a personal journey that seems to parallel a national effort: searching for better ways of providing significant learning experiences for students in higher education. One of my conclusions is that this search would be greatly facilitated if we could find ways of describing our educational goals in terms that would be appealing to the major constituencies in higher education; e.g., faculty members, students, administrators, disciplinary associations, employer groups.

One distinction that needs to be made at the outset is the difference between higher-level learning and active learning. The idea of active 
learning is one of the most important ideas to take hold in American higher education in recent years (Bonwell \& Eison, 1991). The central argument of this movement is that active learning (i.e., having students do something and think about what they are doing) is more powerful in terms of creating significant, lasting learning than is passive learning (e.g., listening, reading). In my view, this argument is totally correct.

However, as important as the concept of active learning is, it is ultimately a concept that is focused on how people learn, not on what they learn. I propose that the higher education community needs a parallel concept that is focused on what students learn, and that an appropriate name for this concept is higher-level learning.

I also need to clarify what I mean by significant learning experiences. When using this term, I am simply referring to what any caring and thoughtful teacher wants for his/her students: a learning experience that will be significant to the students in some meaningful way. One of the goals of this essay is to offer the language of higher-level learning as one way of giving greater focus and direction to this general desire to provide significant learning experiences for students in higher education.

In this essay, I will a) offer some comments on why higher education needs a new way of identifying what constitutes significant learning, b) describe the construction and characteristics of a new taxonomy of higher-level learning that seems to meet this need, and c) point out some of the possible uses of such a taxonomy.

\section{Need for a New Way of Identifying Significant Learning}

As mentioned earlier, I have found myself on a personal journey, searching for a better way of identifying significant learning. My journey seems to parallel a national effort to formulate more significant learning experiences for students.

\section{My Personal Journey}

My own search for better ideas on this topic was jump-started several years ago when someone on campus asked me: "Given all your experience of observing other people's courses, what do you think makes a good course good?" After recovering from the realization that I did not have a ready answer for one of those innocent but profound questions, I began working on an answer and eventually developed a list that I capriciously called "Fink's Five Principles of Fine Courses."

1) Challenge students to higher-level learning 
2) Use active forms of learning

3) Have teachers who interact and communicate well with student

4) Give students frequent and immediate feedback on their learning

5) Have a fair system for assessing and grading students

This list simply reflects my view that, if someone's teaching successfully meets these criteria, their teaching is good, no matter what else is bad about it, e.g., even if a teacher is not enthusiastic or organized. Conversely, if someone's teaching does not meet these five criteria, their teaching is poor, no matter what else is good about it. And for me, the single most important item on this list has always been the first item. If the students are indeed being challenged to, and achieving, something that can meaningfully be called higher-level learning, then the learning experience has been good, no matter what else is bad about the course. The bottom line is that important learning has been achieved.

\section{Events on the National Scene}

In the mid-1980s the National Institute of Education (NIE) urged universities to produce demonstrable improvements, not only in student knowledge, but also in students' "capacities, skills and attitudes" (NIE, 1984). The following year the Association of American Colleges (AAC) suggested a minimum required curriculum, followed by the statement that "we have clearly placed our emphasis on how to learn" (AAC, 1985). A few years later a number of disciplinary associations began issuing calls for similar change. A national study of business management education identified a need for more of the following: leadership and interpersonal skills; ethics; integration across functional areas; and linkages between national spheres, corporations, and local communities, and theory and practice (Porter \& McKibbin, 1988). The engineering profession has modified its accreditation criteria, effective in the year 2000 , to require evidence that students develop, among other things, the ability to function on a multidisciplinary team, communicate effectively, recognize the need for lifelong learning, and understand the ethical character of the engineering profession (ABET, 1998). A commission of the National Association of State Universities and Land Grant Colleges (NASULGC) called on colleges to develop instructional programs that focus on values: "The biggest educational challenge we face revolves around developing character, conscience, citizenship, tolerance, civility, and individual and social responsibility in our students" (NASULGC, 1997). 
Individually authored publications have offered similar statements. For example, after completing a major study on redesigning higher education, Lion Gardiner (1994) noted that society's leaders in business, industry, and government have identified several important kinds of learning needed by citizens and workers in the years ahead. Labeling these as critical competencies, Gardiner's list included a) a variety of personal characteristics (e.g., conscientiousness, ethics, respect for people different from oneself), b) skills (e.g., communication, interpersonal team skills, critical thinking, and problem solving), c) the ability to adapt to change, and d) knowing how to keep on learning.

These several statements are calling on the higher education community to produce a new kind of learning. This new kind of learning will be exciting, but it will challenge faculty members to find new ways of teaching and will challenge students to find new ways of learning.

\section{The Search for a Language to Describe Significant Learning}

As faculty members begin the process of searching for new ways of teaching, we first need a language that will allow us to describe important or significant kinds of learning that make sense across disciplines. Where can we find such a language?

When teachers have pondered this question in the past, they have frequently turned to the well-known taxonomy of educational objectives formulated by Benjamin Bloom and his associates in the 1950s. Although there were in fact three taxonomies (cognitive, affective, and psychomotor), teachers referred to the one in the cognitive domain most often (Bloom, 1956). The cognitive taxonomy consisted of a hierarchy of six levels of learning. These were, from the highest to the lowest:

- evaluation

- synthesis

- analysis

- application

- comprehension

- knowledge (meaning recall knowledge)

This taxonomy has been used both as a framework for formulating 
course objectives and as a basis for testing student learning. Today, when teachers look for ways to go a little further in their courses, they often refer to the taxonomy of higher-level learning offered by Bloom's taxonomy.

There is no question about the value of the accomplishments of Bloom and his associates. Any model that commands this kind of respect half a century later is extraordinary. However, as noted above, individuals and organizations involved in higher education have been expressing a need for important kinds of learning that do not emerge easily from the Bloom taxonomy; e.g., learning how to learn, leadership and interpersonal skills, ethics, communication skills, character, tolerance, the ability to adapt to change, etc.

My interpretation of the aforementioned statements is that they are expressing a need for new kinds of learning, kinds that go well beyond the cognitive domain of Bloom's taxonomy. While the statements call for cognitive learning that is more than knowing and even thinking, there also seems to be a felt need to go beyond the limits of "cognitive" learning itself.

\section{Creating a New Taxonomy}

In order to create a new taxonomy, one that goes further than the Bloom taxonomy, I had to take a different approach than he did. Bloom interviewed teachers about what they thought students ought to know or be able to do, and then created a language that allowed him to categorize and distinguish their responses. But his taxonomy was not related to any model of learning.

I decided it would be important first to create a model of learning that identified distinctive kinds of important learning, and then create a taxonomy based on this model. After reading many statements about what various writers see as significant kinds of learning and interviewing many students about what they found to be significant in their own educational experience, I concluded that there are two distinct dimensions of learning that need to be understood: kinds of change in the learner and the foci of learning. All learning results in some kind of change in the learner, and yet all learning is about something, i.e., is focused on something. I have identified five kinds of change in the learner and five foci of learning that I call the components of learning (See Table 7.1). Understanding these two dimensions of learning can be of great value in explaining why any particular learning might be significant or important for learners. 
TABLE 7.1

A Model of the Components of Learning

\begin{tabular}{ll}
\hline Learning: A Change in . . . & \multicolumn{1}{c}{ Learning about . . . } \\
\hline - Caring & - Learning (i.e., the process of learning) \\
- Acting & - Self \\
- Connecting & - Others \\
- Thinking & - Pdeas \\
- Knowing & Phenomena \\
\hline
\end{tabular}

\section{The First Dimension of Learning: Kinds of Change in the Learner}

The first dimension of significant learning begins with our view of learning itself. If we view the concept of learning as referring to some kind of lasting change in a learner, then we can ask the question: What kinds of change might constitute significant change, i.e., significant learning? There seem to be five kinds of change that need to be recognized: caring, acting, connecting, thinking, and knowing.

Caring. Sometimes as the result of a course or other informal learning experience, people change in the degree to which they care about something. When this happens, the learner acquires new feelings, interests, and/or values about something.

Acting. A student may also develop new abilities to act, meaning a readiness to engage in an action. This may involve learning a new skill (e.g., playing the violin, giving a public speech, or learning how to manage a complex project).

Connecting. At times people learn how to make new connections as the result of their learning. This may come in the form of recognizing similarities among phenomena, ideas, or processes, or noting the interaction among various events or objects.

Thinking. One of the more important changes people report is learning how to think more effectively about some subject. I am using this term as a large umbrella concept that subsumes other more specific kinds of thinking. I like the triarchic view of Robert Sternberg (1989) who recognizes three major kinds of thinking:

- critical thinking, in which people analyze and evaluate something

- creative thinking, in which people imagine and create something new

- practical thinking, in which people apply and use information and ideas; e.g., problem solving and decision-making. 
Knowing. The most familiar change in a learner is coming to know something. By this I am simply referring to what happens when students understand and remember information, ideas, terms, etc.

\section{The Second Dimension of Learning: The Foci of the Learning}

Sometimes, when we learn something significant, it is not because of a change in ourselves as learners, but because of the significance of what we learn about. When we learn, we learn about different things. What are the different kinds of things we can learn about that give significance to our learning? I call these the foci of learning, and have identified five different foci: learning, others, self, ideas, and phenomena (see Table 7.1).

Learning. In some really powerful learning experiences, people learn about learning itself. They may acquire a new understanding of how one learns about a particular subject (e.g., learning about the scientific method), how to be a better student (e.g., regulating one's study time), or how to become a self-directed learner (e.g., setting a learning agenda and developing a plan for achieving it).

Others. Sometimes, either because of the subject matter or because of the way the course is taught (e.g., extensive use of small group interaction), people learn about others. Students can acquire a better understanding of and/or learn how to more effectively interact with important others in one's life. Usually this refers to other people, but it could include other kinds of life as well; e.g., animals, plants, etc.

Self. Students may also learn about their own self. This happens when they develop a new understanding of or feeling about what kind of person they are (a new self-image), or when they acquire a new image of the kind of person they could be and want to be (a new self-ideal).

Ideas. A powerful kind of learning also occurs when students learn about new ideas. By ideas, I am referring to interpretive perspectives that enable a person to construct explanations and/or predictions about objects, events, people, etc. Marxism and evolution are examples of wellknown and important interpretive perspectives.

Pbenomena. The most familiar form of learning is when we learn about a particular phenomenon or phenomena in the realm of the natural sciences (bird, rocks, and weather), the social sciences (individuals, societies, organizations), or the humanities (music, literature, art).

\section{Using the Components to Create a Taxonomy}

Now that we have a clear picture of the components of significant learning, we can use them to construct a taxonomy of higher-level learning. 
TABLE 7.2

Six Important Kinds of Learning

\begin{tabular}{|c|c|c|}
\hline $\begin{array}{l}\text { Key Component(s) } \\
\text { of Learning Involved }\end{array}$ & Special Value & General Label \\
\hline LEARNING & $\begin{array}{l}\text { Provides capability for long-term } \\
\text { continuation of learning. }\end{array}$ & $\begin{array}{l}\text { LEARNING HOW } \\
\text { TO LEARN }\end{array}$ \\
\hline CARING & $\begin{array}{l}\text { Provides the energy (short term } \\
\text { or long term) for learning; with- } \\
\text { out this, norhing significant hap- } \\
\text { pens. }\end{array}$ & MOTIVATION \\
\hline SELF, OTHERS & $\begin{array}{l}\text { Connects one's self to oneself } \\
\text { and to others; gives human sig- } \\
\text { nificance to the learning. }\end{array}$ & HUMAN DIMENSION \\
\hline CONNECTING & $\begin{array}{l}\text { Adds power by connecting dif- } \\
\text { ferent ideas, disciplinary perspec- } \\
\text { tives, people, and/or realms of } \\
\text { life. }\end{array}$ & INTEGRATION \\
\hline THINKING, ACTING & $\begin{array}{l}\text { Allows other learning to become } \\
\text { useful. }\end{array}$ & APPLICATION \\
\hline $\begin{array}{l}\text { KNOWING (esp. } \\
\text { about PHENOMENA } \\
\text { and IDEAS) }\end{array}$ & $\begin{array}{l}\text { Provides necessary understand- } \\
\text { ing for other kinds of learning. }\end{array}$ & $\begin{array}{l}\text { FOUNDATIONAL } \\
\text { KNOWLEDGE }\end{array}$ \\
\hline
\end{tabular}

By grouping a few of the components that seem to be related, we can identify six general kinds of significant learning in a way that makes it easy to recognize the special educational value of each category. Table 7.2 shows the six general groupings that I constructed, and the label that I put on each category. These six categories represent six distinct kinds of significant learning, and as such, give us a new taxonomy of higher level learning.

\section{The Taxonomy of Higher-Level Learning}

These six kinds of learning offer faculty members and instructional consultants a powerful road map for ways of providing significant learning experiences for students in higher education. The resulting taxonomy of higher-level learning (see Figure 7.1) allows us to identify important kinds of learning that most of us would like for students to achieve in our courses and curricula. 
FIGURE 7.1

A Taxonomy of Higher-Level Learning

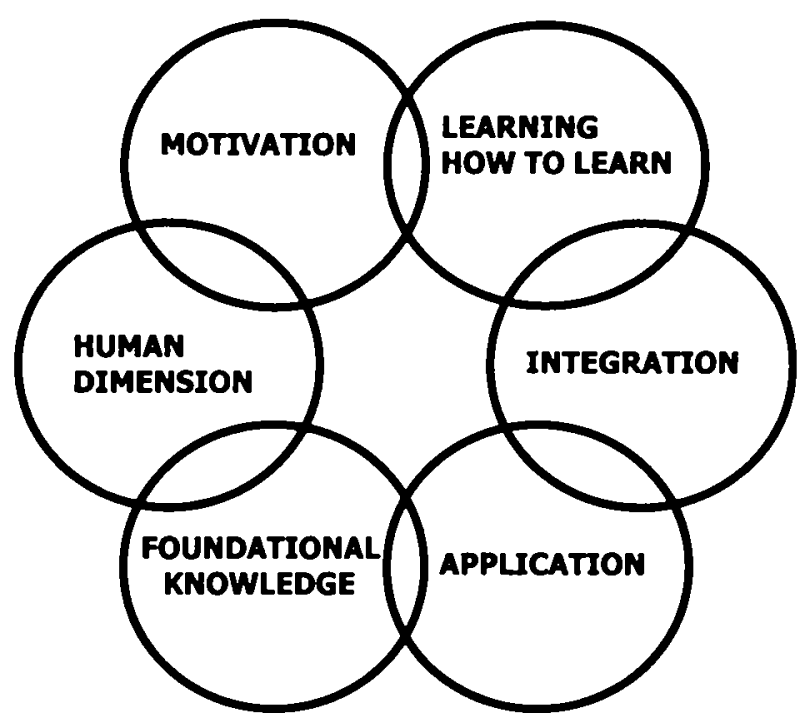

Distinctive Characteristics of the Present Taxonomy

This taxonomy of higher-level learning is different from the Bloom taxonomy in two important ways.

Scope of the taxonomy. First, this one goes well beyond the Bloom taxonomy in the kinds of learning described. The first three types of learning in this taxonomy (foundation, application, and integration) have different labels but in fact are similar to the kinds of learning Bloom described: remembering, understanding, analytical thinking, critical thinking, creative thinking, applying information and ideas, etc. However, the other three categories in the present taxonomy point to new kinds of learning not easily described by Bloom's taxonomy: ethics, leadership, dealing with cultural diversity, self-directed learning, etc. Hence the present taxonomy seems to be better adapted to the expressed educational needs of contemporary society.

Interactive nature. The second significant difference is that the present taxonomy is interactive, not hierarchical. The Bloom taxonomy was always presented as and perceived to be a vertical set: The bottom items were a prerequisite for learning the higher items, and the higher 
items had greater educational value. I do not disagree with the validity of these relationships in the Bloom taxonomy. However, the present taxonomy has a different character. The six kinds of learning in this taxonomy seem to be interactive rather than hierarchical in nature. When viewed this way, all are equal in terms of their general educational value.

This interactive characteristic is very important for teachers because it means the various kinds of learning are synergistic. And this in turn means that teaching is no longer a zero sum game! Teachers don't automatically have to give up one kind of learning to achieve another. Instead, when a teacher finds a way to help students achieve a new kind of learning, this can in fact enhance, not decrease, student achievement in the other kinds of learning. For example, if a teacher finds a way to help students learn how to effectively use the information and concepts in a course to solve certain kinds of problems (application), it is easier for them to get excited about the value of the subject (motivation). Or, when students learn how to effectively relate this subject to other ideas and subjects (integration), it is easier for students to see the significance of the course material for themselves and for others (human dimension).

\section{Educational Goals that Illustrate the Taxonomy}

Another way of understanding the meaning of the taxonomy is to examine some specific goals associated with each category of learning in it. To do this, I will relate the taxonomy to educational goals advocated in the general literature on college teaching, and then show how the taxonomy can be used by teachers to construct goals for their own courses.

\section{Higher-Level Learning and General Educational Goals}

The literature on college teaching contains a large assortment of recommendations for what teachers should be teaching and what students should be learning in college. Each of the proposed educational goals is important, yet each is different from the others in terms of the kind of learning being recommended. Table 7.3 contains a list of several educational goals that various writers have put forth as desirable for college courses and curricula. In this table, I have sorted the goals into groups, according to the kind of higher-level learning that each seems best to express. In this case, the taxonomy seems to help one understand the distinct significance of many different kinds of learning as well as the relationships among them. 


\section{TABLE 7.3}

\section{Educational Goals and the Taxonomy of Higher-Level Learning}

\section{LEARNING HOW TO LEARN}

- How to be a better student (e.g., self-regulated learning, deep learning)

- How to ask and answer certain kinds of questions (e.g., scientific method, historical method, inquiry learning)

- How to be a self-directing or intentional learner (e.g., self-directed learning, selfreflective practitioners, adult learning projects)

\section{MOTIVATION}

- Wanting to be a good student (in a given course and/or in general)

- Excited about a particular activity or subject (e.g., birdwatching, reading history, listening to music)

- Excited about living right (e.g., taking charge of one's life)

\section{HUMAN DIMENSION}

- Character building - Working as a member of a team

- Multicultural education - Citizenship

- Leadership

- Ethics

- Serving others (local, nat'l, world)

- Environmental ethics

\section{INTEGRATION}

- Interdisciplinary learning (e.g., connecting different disciplines, perspectives)

- Learning communities (e.g., connecting different people)

- Learning and living/working (e.g., connecting different realms of life)

\section{APPLICATION}

- Critical thinking

- Creativity

- Practical thinking (e.g., problem solving, decision-making)

- Managing complex projects

- Performance skills (e.g., foreign language, communication, operating technology, fine arts performances, sports)

FOUNDATIONAL KNOWLEDGE

- Conceptual understanding: a full understanding of the concepts associated with a subject, that allows explanations, predictions, etc.

- Deep understanding: an understanding that is anchored in a framework of meaning(s)

\section{Higher-Level Learning and Specific Courses}

It may be hard for an individual teacher to look at all these lofty educational goals and imagine how he or she could possibly incorporate them into everyday courses. But the taxonomy of higher-level learning can help teachers develop a set of goals for their courses that indeed go well beyond the familiar goal of covering the content.

To test this idea, I interviewed a number of teachers on my own 
campus. They all selected courses they frequently taught and then answered some questions about possible goals for that course. The questions focused on each category of higher-level learning. The questions and the responses of one teacher, a professor of microbiology, are shown in Table 7.4 in order to illustrate what their answers looked like.

What I learned from these interviews is that teachers can, with a little guidance, identify specific goals for almost any course that reflect all the categories in the taxonomy of higher-level learning. And in every case, these goal statements represented kinds of learning that the teacher truly valued and, in most cases, went well beyond what the teacher had been using in the past. In sum, the taxonomy was capable of giving direction and impetus to a latent desire of teachers to set more ambitious and yet clearly focused learning-centered goals for their courses.

\section{Using the Taxonomy of Higher-Level Learning}

There are several ways this taxonomy and its associated components can be of value to college teachers, administrators, and students.

\section{Improved Course Design}

The first and most obvious application is to help teachers design courses and curricula that will truly provide students with higher-level learning experiences. One of the first tasks teachers have to accomplish when designing a course is to decide what they want their students to learn or get out of the course. One approach to this task is to list the topics of the course or the powerful concepts introduced in the course. These are of course important. But listing the topics and concepts do not indicate what we want the students to learn about these topics and concepts. The alternative approach to this task is the design approach which begins by asking what it is we want students to learn and then by deciding what teaching/learning strategies would best achieve the desired kind of learning. The ideas and language of higher-level learning can give the teacher a set of tools to describe his/her course goals with more focus and direction. In addition to wanting our students to know something about the subject, do we also want them to also learn how to apply the ideas? Do we want them to learn how to integrate them with other ideas? And so forth.

Also, the model of the components of learning allows teachers to see two clear ways of increasing the significance of their course goals. One 
TABIE 7.4

Higher-Level Learning Goals for a Specific Course

\section{Questions for Formulating Higher-Level Learning Goals}

I. FOUNDATIONAL KNOWLEDGE

- What key facts, terms, formula, concepts, relationships, etc., are important for students to understand and remember in the future?

\section{APPLICATION}

- What kinds of thinking are important for students to learn here:

- Are there other important skills that students need to leam?

- Do students need to learn how to manage complex projects?

\section{INTEGRATION}

- Are there important connections (similarities and interactions) that students should recognize and make?

\section{HUMAN DIMENSION}

- Is there anything you would like for students to learn about themselves?

- Is there anything important that students could or should learn about understanding others and/or interacting with others?

\section{MOTIVATION}

- Are there any changes you would like to see, in what students care about, i.e., any changes in their feelings, interests, and/or values?

\section{LEARNING HOW TO LEARN}

- Are there things you would like for students to learn about

- how to be a good student in a course like this?

- how knowledge is constructed for this particular kind of subject matter?

- how to become a self-directing learner relative to this subject?
Responses of a Microbiology Professor

"A year after this course is over, I want and hope that students will ..."

- ". . remember the terms associated with microbial anatomy, biochemistry, and disease."

- ". . . understand 'orders of magnitude', i.e., what exists at different levels or scales, in relation to other objects."

- ". . . remember the primary categories of organisms."

- ". . be able to critically evaluate bodies of litcrature in academic and popular outlets." (critical thinking)

- “. . be able to mathematically calculate the rate and extent of microbial growth." (skill)

- ". . . integrate ideas about energy, from chemistry and microbiology."

- ". . . relate ideas about microbial biology with processes in higher organisms, e.g., metabolism, disease."

- ". . . come to see themselves as people who are more educated about microbiology than the average lay person.

- ". . . be able to inform and educate other intelligent citizens about the role of microbiology in personal and public life; e.g., educate their roommates about proper ways of cooking hamburger."

- ". . . be excited about microbiology as a broad, complex, multifaceted field of study; i.e., a subject that is concerned with more about organisms than just their role as causes of human diseases."

- ". . value the importance of precise language in this field of work, as part of professional ism."

- ". . . be able to know how to read assigned material responsibly." (being an effective student.)

- ". . know how the scientific method works, especially the importance of identifying and testing the hypothesis." (a method of learning that is particular to this subject matter.)

- ". . . be able to identify important resources for their own subsequent learning." (becoming a self-directing learner.) 
way is by trying to promote more significant forms of change in the learner; i.e., more than just knowing. The second way is by increasing the foci of the course, learning about more than just the phenomena that constitute the subject of the course.

\section{Better Basis for Choosing among Alternative Teaching Strategies}

During the last few decades, the scholarship of teaching in higher education has generated a wonderful array of new and exciting ways of teaching: problem-based learning, writing across the curriculum, team learning, experiential learning, collaborative learning, computer-based learning, and so on. While this has created a wealth of choices, the very extent of the options can also be overwhelming. They all look good, yet one cannot do them all, at least not simultaneously. So how does a teacher choose among them? The answer I would give to that question is to use higher-level learning as a criterion. Which approach to teaching seems likely to promote the most kinds of higher-level learning, in the greatest depth? For example, if one approach seems to offer good foundational knowledge and good application learning, but a second approach offers both of these plus better learning about the human dimension and learning how to learn, then I would definitely choose the latter option over the former.

\section{Bigger Perspective of the Literature on Teaching and Learning}

The literature on teaching and learning in the last three decades or so has grown tremendously and truly has blossomed a "thousand lights." However, this very wealth of ideas creates the need for some kind of conceptual framework that will allow us to see the relationships among these different ideas more clearly. It would seem that the taxonomy of higherlevel learning could be very helpful in this regard.

As shown in Table 7.3, the extended list of educational goals receiving much national attention at the present time can be sorted into different groups, based on the kind of higher-level learning that is the central feature of each particular goal. Having the bigger picture in mind when reading about any one of these allows us to appreciate its special value without being misled into believing that it is the whole of significant learning.

\section{A New and Better Basis for Evaluating Teaching}

Academic departments and teachers continuously face the unenviable task of having to evaluate teaching, without the benefit of a shared vision 
and language for describing what constitutes good teaching and good learning. As a result, the default criterion has become: "How well do students like the teacher or the course, relative to other teachers and other courses?"

Although I strongly believe that student reaction to teaching is an essential component of a full evaluation of teaching, I think a significantly better criterion would be: "Was a particular course or teacher effective in terms of promoting higher-level learning?" When the answer to this is "yes," then the course or teacher was successful-regardless of whether the lecturing style was good or not, whether he or she lectured at all, or whatever. And conversely, when a course does not promote much higher level learning, then there is a problem that needs to be addressed by the teacher-again, regardless of how good the lectures were, how popular he or she was with students, etc.

The bottom line when evaluating teaching should be: Did significant learning occur or not? And the taxonomy of higher level learning gives us a language with which we can address this question, applicable across disciplines.

\section{Guiding Student Reflections on Their Own Learning}

One of the rapidly emerging lessons in the realm of active learning is that students need to periodically reflect on their own learning, asking such questions as, "What am I learning in this course? Of what value is it? How do I connect this learning to previous learning and to future activities? What else do I need to be learning in the near or distant future?" One-minute papers, student journaling, and learning portfolios all address the need for students to reflect on their own learning, in increasing levels of scope and extent.

However, as students reflect on these questions, they are likely to find significant value in a conceptual framework that will guide their reflective thinking. I have had a few experiences thus far suggesting that the model of the components of learning (Table 7.1) can in fact provide a very rich road map to this kind of reflection.

I recently had occasion to interview a pair of students who had participated in a summer internship in Washington, DC, and who were trying to prepare future interns. During the interview, I posed a series of questions focused on each of the components.

1) During the time you were working as an intern, how did you change, in terms of 
- what you care about differently now, than you did before?

- what actions you are capable of performing now?

- what you can connect or integrate now, that you could not before?

- your ability to think about problems in political science?

- what you know?

2) What did you learn about

- the process of learning about politics?

- interacting with other people?

- yourself?

- some of the major ideas you studied in political science?

- the phenomena involved (in this case, politics)?

The answers from the two students were different from each other, very focused, and very rich.

I came away from this experience convinced that the components of learning can provide a good road map for helping learners acquire a better understanding of what they have learned in a rich learning experience. This in turn positions students well to work on the question of what they need and want to learn next. It also feeds well into the general effort of finding ways to help learners become more effective as self-directed, intentional learners.

\section{Conclusion}

In one of the most widely read articles on higher education in recent years, Barr and Tagg (1995) describe what they believe to be a major change taking place in American higher education. This change is a paradigm shift in which institutions are thinking less about providing instruction (the teaching paradigm) and more about producing learning (the learning paradigm). This paradigm shift, to the degree that it is in fact occurring, creates a new need. The real need, though, is not just to produce learning, but to produce significant learning.

My belief and hope is that the model of higher-level learning described here has the potential for giving us the critical first step toward more significant learning: a language and set of values for describing the goals of learning experiences that most people can accept as being truly 
significant. College and university faculty will still need to learn how to translate this general language into specific terms for particular courses and curricula. And they will need to learn how to use multiple forms of active learning and new forms of feedback and assessment, in order to make these new, more ambitious goals a reality. But if they can learn how to do all that, the result should be a significantly different and much more exciting form of education than is often the case at the present time.

\section{REFERENCES}

AAC (Association of American Colleges). (1985). Integrity in the college curriculum: A report to the academic community. Washington, DC: Association of American Colleges.

ABET (Accreditation Board for Engineering and Technology). (1998). Criteria $2000,\left(3^{\text {rd }}\right)$. Baltimore, MD: Accreditation Board for Engineering and Technology.

Barr, R. B., \& Tagg, J. (1995). From teaching to learning-A new paradigm for undergraduate education. Change, 27 (6), 13-25.

Bloom, B. S. (Ed.). (1956). Taxonomy of educational objectives. The classification of educational goals. Handbook I: Cognitive domain. New York, NY: David McKay.

Bonwell, C. C., \& Eison, J.A. (1991). Active learning: Creating excitement in the classroom. ASHE-ERIC Higher Education Report 1. Washington, DC: George Washington University.

Gardiner, L. (1994). Redesigning higher education: Producing dramatic gains in student learning. ASHE-ERIC Higher Education Report 7. Washington, DC: George Washington University.

NASULGC (National Association of State Universities and Land-Grant Colleges). (1997). Returning to our roots: The student experience. Washington, DC: National Association of State Universities and Land Grant Colleges.

NIE (National Institute of Education). (1984). Involvement in learning: Realizing the potential of American highereducation. Washington, DC: National Institute of Education.

Porter, L. W., \& McKibbin, L. E. (1988). Management education and development: Drift or thrust into the 21st Century? New York, NY: McGraw-Hill.

Sternberg, R. J. (1989). The triarchic mind: A new theory of human intelligence. New York, NY: Penguin. 
Contact:

\section{Dee Fink}

Director, Instructional Development Program

Hester Hall, Room 203

University of Oklahoma

Norman, OK 73019

(405) $325-2323$

(405) 325-7402 (Fax)

Email:dfink@ou.edu

Dee Fink has been Director of the Instructional Development Program at the University of Oklahoma since it was established in 1979. He has done work on student learning, new faculty members, the evaluation of college teaching, and instructional design. He has co-directed the workshop on getting started at the annual POD conference since 1992. During the past year or so, he has been leading campus workshops on how to design instruction for higher-level learning. In his own life, he is exploring the relationship among spirituality, leadership, and learning. 